\title{
Periodismo heroico, moral y virilidad revolucionaria: la juventud y la mujer en la revista Por Qué?, 1968-1974
}

\author{
Heroic Journalism, Moral and Revolutionary Virility: \\ Youth and Women in the Magazine Por Qué?, 1968-1974
}

\author{
Juan Carlos Sánchez Sierra \\ Facultad de Ciencias Económicas y Sociales \\ Universidad de La Salle (Bogotá, Colombia) \\ jcarlosssierra@gmail.com
}

\begin{abstract}
Resumen
A través de un abordaje conceptual y empírico, en este artículo se propone un análisis de las transformaciones del periodismo de oposición entre las décadas de 1960 y 1970 a la luz de Por Qué?, una de las publicaciones más representativas de la época. Además de contener un tono paternalista y condescendiente, el examen del discurso moralista del periodismo de oposición evidencia cómo la izquierda, al promover entre jóvenes y mujeres la adopción de posiciones críticas frente al régimen político mexicano, construía un ideal de periodismo heroico que era refrendado por los efectos de la represión entre sus más notables líderes. Esta investigación propone algunas líneas de interpretación sobre la progresiva formación de un periodismo alternativo a la "gran prensa" favorecida por el régimen, y el papel que el periodismo heroico jugó en la idealización de subjetividades que vehiculadas en un ideal revolucionario mantuvieron marginada la participación femenina y juvenil en el ámbito político mexicano.
\end{abstract}

Palabras clave: Periodismo; heroísmo; izquierda mexicana; subjetividad; masculinidad.

\section{Abstract}

This article uses a conceptual and empirical approach to analyze the transformation of opposition journalism in the 1960s and 1970s, through the magazine Por Qué?, one of era's most representative publications. A study of the moralistic discourse of opposition journalism reveals its paternalist and condescending tone, but also shows how, by encouraging youth and women to adopt critical positions towards the Mexican political regime, the left constructed an ideal of heroic journalism that was reinforced by the effects of the repression of its most notable leaders. This research proposes several lines of interpretation of the progressive creation of an alternative journalism to the "mainstream press" favored by the regime, and the role played by heroic journalism in idealizing the subjectivities contained in a revolutionary ideal, which kept women and youth in a marginal position in the Mexican political sphere.

Key words: Journalism; heroism; Mexican left-wing; subjectivity; masculinity.

Fecha de recepción: 11 de mayo de 2013 Fecha de aceptación: 22 de julio de 2014 


\title{
Periodismo heroico, moral y virilidad revolucionaria: la juventud y la mujer en la revista Por Qué?, 1968-1974
}

\author{
Juan Carlos Sánchez Sierra
}

\section{INTRODUCCIÓN: EL PERIODISMO DE LA ÉPOCA Y EL CONTEXTO DE SURGIMIENTO DE POR QUÉ?}

$\mathrm{E}$ ste artículo propone una lectura de la crisis de la izquierda posterior al movimiento de 1968 desde el examen de los discursos morales y los perfiles de masculinidad revolucionaria que fluyeron en las páginas de la revista Por Qué? Entre 1968 y 1974 esta revista representó una nueva orientación en la izquierda mexicana y el periodismo de oposición que buscaba el cambio de las estructuras sociales y políticas de México a través del activismo, la denuncia y la exaltación de la lucha guerrillera. Esta forma de hacer periodismo, que intentaba calar en un público juvenil reacio a los grupos de oposición tradicionales, fue ampliamente criticada por la izquierda y perseguida por el régimen político. Mario Menéndez, director de la revista Por Qué? y quien gustaba de caminar sobre la fina línea que divide la denuncia política y el sensacionalismo amarillista, sirve en este trabajo como ejemplo para explorar la formación de subjetividades revolucionarias donde el papel del periodista se ensamblaba con ideales de heroísmo, sacrificio y entrega a una causa política, características que privilegiaban la figura masculina como síntesis del heroísmo revolucionario y que relegaron lo femenino a un espacio marginal y lleno de ambigüedades en el horizonte de rebeldía de la década de 1970 (Trejo, 1975, pp. 26-34).

Para ubicar el nacimiento de Por Qué? en la primera mitad de 1968, es necesario involucrar en el análisis las transformaciones experimentadas en la práctica del periodismo, "toda vez que [Por Qué?] constituyó la versión oficial de la izquierda mexicana sobre el movimiento estudiantil durante las siguientes dos décadas" (Castillo, 2013, p. 163). La revista formaba parte de una saga de publicaciones que adquirieron influencia desde finales de la década de 1950, entre las que se pueden incluir Sucesos, Problemas Agrícolas e Industriales de México y, en los años 1960, la revista Política. Lo que las carac- 
terizaba reposaba en sus páginas, pues en ellas se ejercía el oficio desde el margen izquierdo ideológico, siguiendo derroteros morales afines a las necesidades del país y Latinoamérica. Mientras Sucesos fue uno de los espacios en los que Mario Menéndez perfiló una actitud audaz de la mano del esfuerzo gráfico de fotógrafos que luego lo acompañarían en Por Qué? (Castillo, 2012, pp. 74-80; Mraz, 1997 pp. 111-113; Salgado, 1990, pp. 17-56), Problemas Agrícolas dio más importancia al examen profundo de los factores económicos y políticos que se cernían sobre la sociedad mexicana (Perzabal, 1997, pp. 6471; Rivera, 2004). En ambos casos, periodistas y reporteros gráficos eran una constelación de visiones de la época, adscritos ideológicamente a los preceptos de la revolución cubana. Luego, muchos de ellos tuvieron en Política la continuidad necesaria para instalar un perfil moralmente adecuado para la práctica del oficio (Cabrera, 2006; Gutiérrez y Borrás, 2001; Reynaga, 2007; Rodríguez, 2007; Sánchez, 2013). La conformación de los equipos periodísticos también da cuenta de una secuencia en la emergencia y declinar de publicaciones de oposición que sirvieron para erigir el marco de valores para caracterizar su heroísmo en la vida pública mexicana de los años 1960 y 1970. Por ejemplo, como lo señala Salgado (1990, pp. 21-27), en Sucesos se reunieron columnistas como Juan Duch, Rosendo Gómez Lorenzo, Víctor Rico Galán, Vadillo y Rius como caricaturistas, Ermilo Abreu, y en la parte de fotografía Rodrigo Moya y Armando Salgado (Castillo, 2011; Salgado, 1990); todos ellos se vincularon posteriormente a Política, luego de su fundación en mayo de 1960. Así, Por Qué? completaba una promesa común, un pacto de caballeros: mantener la voz de la oposición.

En un esfuerzo por la autonomía y la renovación de la profesión, Por Qué? hizo de las fallas de dichas publicaciones uno de sus nichos periodísticos, y atrajo precisamente lectores que empezaban a cuestionar el armazón moral y autoritario de la democracia mexicana visto como "el aparato represivo propio del terrorismo de Estado". Más que arrogarse ser abanderada de ese lugar indefinible y fugaz llamado la nueva izquierda, sus páginas evocaron los temas que empujaban a muchos jóvenes a las calles a protestar por una inconformidad latente pero a menudo inasible en palabras, conceptos o lealtades ideológicas, pues según señalaba León Guzmán, el Estado estaba aniquilando a la juventud, que era "la fuerza viril revolucionaria de la patria”. Por ejemplo, Ramón Costa Ayube ofreció un examen de la conducta juvenil frente a la asimilación del ejemplo de los adultos como una cuestión en la que se reflejaba "un problema estructural y moral de la sociedad". La juventud, el régimen, las ideologías, todos se arremolinaban sin vaticinar la

\section{(이요 $(3$}


masacre. Para Fausto Trejo, lo necesario para que los jóvenes vislumbraran ese porvenir democrático y con justicia social, lo importante, estaba en forjar un periodismo alternativo a la educación existente, con valores que dieran principios morales a la juventud y que debían iniciar en casa, donde se debía evitar la doble moral que practicaba el gobierno, y así formarlos en elementos necesarios para la toma de conciencia como pauta para la madurez de una "juventud viril que expresa su inconformidad". Otra opinión periodística buscaba examinar el creciente poder de los medios de comunicación, que determinaban la formación de rasgos en el carácter infantil; el argumento del artículo consideraba entre lo espiritual, lo cognitivo y lo moral la combinación de una batalla en la formación infantil, "la conciencia del futuro"; el autor explica así la obsesión televisiva de la época como resultado de las fracturas en la unidad familiar y la erosión de valores que los menores aprendían por imitación. El periodismo de Por Qué? buscaba resolver los problemas de México a través de un acercamiento más explícito de la juventud a los problemas sociales, proceso en el que el periodismo desempeñaba un papel central así como en la interpretación de esas nuevas visiones del mundo.

Por Qué? vio la luz pública meses antes del desenlace del movimiento estudiantil-popular de 1968, y rápidamente se convirtió en un órgano de expresión popular, a la vez que sirvió para ejercer presión sobre el régimen y el periodismo oficial de la "gran prensa" (Castillo, 2013, pp. 149-178; Rodríguez, 2007, pp. 179-1956; Trejo, 1975, pp. 9-17). De esa convergencia y merced a su contenido menos académico o intelectualizado, surgió esa asociación de la revista como el medio escrito y gráfico portaestandarte del periodismo crítico y políticamente comprometido con la construcción de unos principios democráticos para el país. La revista nació alimentada de los procesos propios de una dinámica modernizante y del florecimiento de ideologías de mitad del siglo xx (Agustín, 1991, pp. 134-178). La dirección de la revista buscaba complementar los aportes significativos que hicieron las revistas de oposición mencionadas, y en especial Política, que favorecieron la configuración de una esfera pública alternativa en México (Negt y Kluge, 1993, pp. 17-28), para así marcar una diferencia con respecto a sus inclinaciones hacia las tendencias más representativas de la izquierda.

Inspirada en un diseño editorial innovador, la calidad visual de Por Qué? contrapesaba la desigualdad entre número y número del valor analítico de las columnas de sus colaboradores; mientras los baluartes intelectuales de los años 1960 hicieron de Política, Revista de la Universidad, Siempre!, La Cultura en México y El Gallo Ilustrado -suplemento dominical del diario El

\section{(이요 $\$$}


Día- las plataformas predilectas para sus opiniones, para finales de 1968 se desconfiguró el periodismo de oposición por el temor a represalias gubernamentales propias de la época de agitación que se vivía. Las retiradas de colaboradores indignados que despreciaron al régimen por su brutalidad, y el silencio de la profesión que se sucedió a la masacre de 1968 dan fe de un momento de grandes dificultades, riesgos y temores, factores que emocionalmente incitaban a la consideración del oficio como una epopeya con visos de tragedia (Cano, 1995, pp. 13-36; González, 1971; Leñero, 1978). El legado crítico del oficio entonces se dispersó en iniciativas clandestinas o marginalizadas por la presión económica o la homilía que debían cumplir para obtener papel o el guiño favorable de alguna prensa que les hiciera la caridad. Esta postración se mantuvo hasta 1972, cuando, por un esfuerzo colectivo que a su vez integraba ideas divergentes pero unificadas en su ardor opositor, entre muchas otras apareció Punto Crítico para revivir las esperanzas subterráneas de intelectuales, académicos y políticos dedicados a escribir contra el poder (Hiriart y Bellinghausen, 1988, pp. 164-207; Trejo, 1975, p. 45).

Así, la contribución de Por Qué? a la sociedad mexicana se podría sintetizar en tres aspectos. En primer lugar, dar continuidad a un periodismo que se legitimaba en la oposición al régimen político y sus órganos de prensa acríticos y adictos al esquema de sobornos que se había configurado desde el siglo xix (Alba, 1967; Díaz, 1990; Jaimes, 2012; Orme, 1997; Pérez, Piccato y Castillo, 1997; Rodríguez, 1993); la incorporación de variaciones en las versiones informativas, y por ende en la profundización interpretativa, para dar paso a las facetas de una verdad socialmente construida, que serviría en los años 1960 y 1970 como un medio de contención al poder omnipresente del gobierno y a la verdad que le interesaba difundir con su "gran prensa". Finalmente, al ofrecer continuidad a las alternativas informativas disponibles para las capas sociales que consumían información, permitió que la esfera pública mexicana floreciera para fortalecer los llamados a un cambio en la estructura de poder del país, en la que ya no sólo tenían voz los sectores tradicionales, sino que incorporaba a jóvenes y mujeres en la definición del rumbo que más le convenía a México (Dahlgren y Sparks, 1991, pp. 10-29). Aunque estos factores fueron benéficos, pudo más el poder represivo del régimen, que hostigó y marginó estas alternativas informativas mientras apaleaba las expresiones sociales que buscaban rejuvenecer el panorama sociopolítico de la época.

Este artículo busca establecer hasta qué punto la revista Por Qué? fue fiel a estos preceptos, y la manera en que, en sus páginas y en el accionar

\section{(이요 $(3$}


de los periodistas que animaron esta empresa periodística, se manifestaban barreras que impedían un diálogo fluido, en particular con los jóvenes y mujeres que reclamaban espacios de expresión, cambio social y la renovación del proyecto nacional.

\section{PERIODISMO HEROICO Y SUBJETIVIDAD REVOLUCIONARIA EN POR QUÉ?}

Un punto que permite contrastar la emergencia de un periodismo alternativo y la activación de jóvenes y mujeres en la escena política mexicana fue la manera como el director de Por Qué? personificaba el papel del periodista heroico mientras se iba construyendo un sitio especial en la vida pública para los opositores al régimen. Aunque la participación de Mario Menéndez en el periodismo se puede trazar en la relación que su familia tuvo con los medios de comunicación en Yucatán, fue en el Distrito Federal cuando durante su desempeño en Sucesos dejó ver muestras de arrojo. Allí vino a suceder a Raúl Prieto como director, un designio auspiciado por su propietario Gustavo Alatriste, y el cambio determinó una radicalización temática merced a un grupo de reporteros "sin pelos en la lengua" que promovían denuncias de corrupción, algo que aumentó el tiraje e interés del público que, según señala uno de sus más reconocidos reporteros gráficos, permitió que el estilo de Menéndez "se dejara venir como oleada" (Salgado, 1990, pp. 21-22). Mario Menéndez, al igual que sus aliados, son ejemplos interesantes que permiten comprender el valor que adquirió el oficio periodístico en los años 1960.

Si se consideran algunos elementos presentes ya sea en la prensa de la época -columnas, editoriales, caricaturas-, la literatura relacionada con el tema (Bolaño, 1999, 2004; Leñero,1978;), o los rastros de crónicas (Salgado, 1990 ) y la recopilación de su mención en las investigaciones existentes (Cabrera, 2006; Castillo, 2011, 2013; Gutiérrez y Borrás, 2001; Rodríguez, 2007; Sánchez, 2013; Trejo, 1975) se hace evidente que los periodistas cada vez arriesgaban más por el privilegio de la noticia, en un medio hostil que les mezquinaba las posibilidades mínimas de la libertad de expresión.

En medio de esas dificultades, y con el augurio de los beneficios de una moralización del oficio, el contexto ideológico favorecía la articulación de las narrativas periodísticas con las dificultades experimentadas en la búsqueda de una transformación política y social. Así, las tribulaciones de la represión, la escasez de papel, el secuestro de ediciones enteras para evitar

\section{(1)(1)}


su circulación, la captura y amedrentamiento a reporteros, redes de delación que incluían a voceadores y miembros de los organismos de seguridad y periodistas afines al régimen, eran factores que obstaculizaban el ejercicio del oficio, y el uso de la libertad de expresión. Cuando los periodistas tenían definidos derroteros ideológicos revolucionarios, ya reconocían figuras que en otros países del mundo incitaban mistificaciones apropiadas para la utopía socialista o comunista, y al ensoñar el cambio revolucionario se asumían como hombres nuevos que debían entregar sus mejores esfuerzos o incluso sus vidas en el oficio del periodismo en la construcción revolucionaria (Cranston, 1972, pp. 6-46; Fromm, 1998, pp. 17-34 y 56-91). El paradigma del nuevo humanismo vigorizaba las posturas filosóficas revolucionarias, por lo que se podría sugerir que el ideal del Hombre Nuevo servía al nivel subjetivo como el personaje que marcó la construcción de las narrativas necesarias para poblar la épica revolucionaria con las acciones de intelectuales que normalmente se separaban de la acción (Kosik, 2012). El periodista, como Hombre Nuevo, ya no ocupaba un lugar intermedio entre el intelectual distanciado de la realidad absorto en la reflexión y el luchador enlodado en los tremedales de la realidad, sino que adoptaba una postura más activa, punzante, transformadora de la realidad pese a sus adversidades. El nacimiento del Hombre Nuevo tenía en el periodista heroico la oportunidad de saldar las desavenencias de la falta de acción y el compromiso del hombre urbano.

Esta investigación no pretende negar los sufrimientos y aberraciones de los derechos de expresión a los que fueron sometidos periodistas y colaboradores de revistas de izquierda en el periodo estudiado. Tampoco se busca ocultar las violaciones a los derechos fundamentales a los que se sometió a los presos políticos. El peso aplastante del esfuerzo gubernamental por acallar voces alternativas se notó en su incapacidad para incorporar las demandas sociales por una apertura democrática, y allí los medios fueron el mecanismo social de denuncia y activación social, lo que conllevó a represalias brutales que sería baladí siquiera controvertir. Sin embargo, una democracia se construye a través de la visualización plena de los logros y fracasos de los intentos de ampliación de la esfera pública, y allí la izquierda mexicana padeció limitaciones sobre las que se debe arrojar luz para así esclarecer los problemas que constantemente enfrenta una sociedad debatida por contradicciones que merecen atención y superación. Más bien, el objetivo de este artículo es examinar las condiciones del ejercicio periodístico críticamente, de forma que sea posible entender un problema histórico que merece la atención de los investigadores sociales, sin caer en la reproducción inane de un

\section{(이요 $(9$}


discurso apologético, acrítico, que durante décadas ha predominado (Cohen y Frazier, 1993, pp. $75-105 ; 2004){ }^{1}$

Por periodismo heroico aquí se entiende la construcción social de una percepción de notabilidad y reconocimiento que favorecía a los practicantes de la profesión, y por la cual sus acciones, planteamientos ideológicos, y condición política, los designaba como figuras públicas sobre las que había recaído tanto el empuje para reanimar la idea de "lo revolucionario", como el peso de las represalias que esto podía desencadenar. Lo heroico del periodismo está definido tanto por el carácter público de la lucha por restablecer un orden revolucionario, como por la represión ejercida por el régimen político existente. Como se señalará más adelante, esta fue una condición importante que determinó al menos tres procesos que aquí se estudian. En primer lugar, el tono editorial de Por Qué? entre las publicaciones de la izquierda -el caso de la prensa oficialista y de la oposición conservadora, su tono moralista tampoco ha sido estudiado-, particularmente en lo relativo a las prescripciones morales con las que se analizaban temas sobre la juventud y la mujer en la revolución. En segundo lugar, el periodismo heroico se convirtió en una de las facetas más importantes en la construcción de subjetividades revolucionarias durante las décadas de 1960 y 1970 en México, que limitaron el espectro de reconocimiento principalmente a hombres adultos. Esto hizo del periodismo de izquierdas un campo de batalla homosocial donde los discursos moralistas servían como vehículos para limitar "lo revolucionario" a ciertos valores sinónimo de virilidad, resistencia y sacrificio. ${ }^{2}$ Finalmente, el escenario para la formación de esta subjetividad heroica que privilegiaba a los periodistas varones era una esfera pública alternativa, en la que discursivamente se hablaba y definía a mujeres y jóvenes, pero limitando su autonomía en la acción política (Cohen y Frazier, 2004; Sánchez, 2013, 97-144).

${ }^{1}$ Este artículo busca complementar la línea de análisis e interpretación avanzada por estos investigadores estadunidenses. Los principales elementos de su argumento se desarrollarán en las secciones siguientes.

${ }^{2}$ La idea de un "periodismo heroico" es una aporía. El ejercicio periodístico siempre será heroico en tanto veamos al poder como un leviatán que devora a los que lo desafían, y al periodista como alguien que le arrebata al establecimiento la luz de la verdad. Ambas son posiciones morales clásicas de la filosofía política, que en el siglo xix fueron retomadas en debates sobre el papel del intelectual en la construcción de una sociedad justa, y la función del liderazgo político como conducción de masas entre los principales elementos del pensamiento político liberal progresista.

\section{()(1) $\$$}




\section{EL ESCENARIO: EL LUGAR DE POR QUÉ? EN EL PERIODISMO DE IZQUIERDAS}

La revista Política, dirigida por Manuel Marcué Pardiñas, marcó el sendero del periodismo de la década de 1960 al adoptar no sólo una perspectiva de oposición al sistema, sino además en el interés de acondicionar a sus lectores en términos políticos e ideológicos con los elementos ilustrativos de la crisis nacional (Perzabal, 1997). Inspirada en la revolución cubana, Política gestó la convergencia de tendencias de la izquierda dispersas y en constante fragmentación, en particular a la luz de los hechos que llevaron a prisión a los líderes más reconocidos del sindicalismo insurgente de 1958-1959 (Castillo, 2013, pp. 150-154; Reynaga, 2007, pp. 37-50; Rodríguez, 2007, pp. 81-85; Trejo, 1975, pp. 40-43). En 1960 se sumarían al listado de presos políticos de la insurgencia sindical David Alfaro Siqueiros y Filomeno Mata, lo que desnudó los rasgos de la lucha política y periodística característicos de la década y en adelante, hasta finales de los años 1970. Fue en las páginas de Política donde se dio contorno a los rasgos del periodismo heroico como uno de los principales aspectos de la subjetividad revolucionaria del México contemporáneo (Sánchez, 2013, pp. 102-111). Fenómenos como la incesante exaltación del sacrificio que implicaba mantener una posición política autónoma, la virilidad que otorgaba la lucha, erigieron la reportería y la opinión editorial como profesiones donde se requerían los valores de rebeldía y efervescencia -muestra de una perpetua juventud-contra el poder político. También se enaltecía el ejercicio profesional a niveles equiparables a los de la lucha armada clandestina o la conducción de las masas en una faena insurreccional.

El periodismo heroico requería forjar un medio que le fuera afín. Esto dio lugar a un patrón común de acción en el periodismo de la oposición marcado por la habilitación de gestas y personajes, el uso de los medios impresos como una plataforma pedagógica para elevar el nivel político e ideológico del debate entre militantes, la exhibición de preceptos que garantizaban la "altura moral" del revolucionario comprometido, y finalmente la reiteración de temas como el de la juventud y la mujer en la revolución. La familia, la moral y el proyecto revolucionario colmaban el mundo del periodista, todos presentes en el relato de Armando Salgado, eran completados por los temores y debilidades y sufrimientos que daban dinámica a esta escenificación del accionar revolucionario del periodista de la década de 1960. Este punto merece particular atención, pues fue allí donde el periodismo opositor intentó -a través de un discurso moralista cargado de paternalismo y con-

\section{(이요 $\$$}


descendencia- resolver las falencias del régimen al no involucrar a jóvenes y mujeres como actores protagónicos en la definición del rumbo del país, de esa revolución frustrada, pospuesta o incompleta secuestrada por el régimen antidemocrático del PRI. El problema estuvo en que no proporcionó espacios amplios y equitativos a mujeres y jóvenes, y más bien se plegó a algunas de las prácticas tradicionales del poder político en México para reproducirlas en continuidad con el autoritarismo patriarcal del régimen. El resultado de este proceso fue dual: mientras el periodismo se erigía como la fuente de resignificación del concepto de revolución, ocurrió una metamorfosis de los cimientos sobre los que reposaba la práctica de la profesión misma.

A lo largo de la década de 1960, el periodismo de izquierda pasó de tener un papel social marginal, a convertirse en una esperanza para recobrar la lozanía de la trajinada libertad de prensa y expresión. La decadencia ética en la que el partido de gobierno postró a sus periodistas -la "gran prensa"contrastaba con la idea repetida en los medios según la cual los profesionales agitaban al pueblo exaltando los valores de la rebeldía social, como parte de la cristalización de la moral revolucionaria en el panteón de los prohombres del poder del PRI (Sánchez, 2013, pp. 130-138). El punto de diferenciación de la prensa de izquierdas estaba en un marco ético y moral que lo hacía característico. La dignificación de valores como el compromiso político, el aguante frente a los embates de la represión, la resistencia a los seductores llamados del régimen por la vía de la cooptación, y el reconocimiento social que empezaban a recibir aquellos que hacían su trabajo por el poder de sus convicciones y sin manipular la información, significaban un lugar social que ganaba un sitio privilegiado (Orme, 1997, p. 81).

\section{TRAS BAMBALINAS: UN PARTICULAR PROTAGONISMO DE JÓVENES Y MUJERES EN POR QUÉ?}

Absorto en los riesgos de su accionar, el periodista heroico perdía de vista a aquellos que lo acompañaban en la senda revolucionaria. Además de lo que se puede inferir por los trabajos de Vicente Leñero y Roberto Bolaño, el papel de la mujer era marginal, cuando no anulado por el predominio masculino en el ámbito social de reconocimiento a la profesión del periodismo (Bolaño, 2004; Leñero, 1978; Scherer, 1986, pp. 43-60). Durante la misma década, como señaló Carlos Perzabal en las memorias sobre la revista Política, el caso

\section{()(1) $(2$}


de Raquel Tibol y la presión que recibió de parte de Manuel Marcué Pardiñas y David Alfaro Siqueiros permite intuir que las condiciones no podían ser distintas en publicaciones que se sostenían incluso con mayor precariedad como en el caso de Por Qué? (Perzabal, 1997).

En Por Qué? ese papel de jóvenes y mujeres aparece marcado por ambivalencias. Las exaltaciones del movimiento estudiantil de 1968 sirvieron en sus páginas más bien para resaltar facetas del divisionismo de la izquierda antes que para unir esfuerzos. Abundaron expresiones de júbilo que negaban el estereotipo de la rebeldía juvenil como "sin causa", como en el caso de Horacio Espinosa Altamirano, quien señalaba que la lucha insurgente no era aventurerismo, sino "el signo de una nueva época" en la que los jóvenes antepondrían sus principios a través de un lenguaje ético, estético y político incomprendido y malinterpretado por los regímenes, que terminaban por aplastarlos. ${ }^{3}$ Esta concepción instrumental del ardor juvenil le significó una difícil trayectoria al periodista, pues aun en nuestros días es visto como irresponsable y radical por buena parte de la izquierda del país. De otra parte, en este caso una celda, pero no con menos furor en la sangre, Federico Emery denunció cómo el PCM traicionó al movimiento estudiantil y le dio la espalda a los jóvenes, no sólo al tener una participación ambigua y sobre todo oportunista al arrogarse ser inspiración ideológica, parte y líder de la movilización, sino además como una demostración del lastre que los partidos de izquierda -y en especial los de línea pro soviética- representaban para "los esfuerzos heroicos de una juventud que tiene claro el horizonte revolucionario". ${ }^{4}$ Hasta aquí los jóvenes no son actores, sino más bien instrumentos de nada para la guerra de retaliaciones de la izquierda.

En la misma dirección, el artículo de Rodolfo Montalvo Reyes se dirigió como una sentida celebración de la capacidad juvenil para luchar, para luego desbordarse en críticas contra el PPS como "el palero del PRI", y condenó al venerado Vicente Lombardo Toledano de ser un "ecléctico camaleón" que buscaba a cualquier precio ajustar su línea política a las veleidades del partido de Estado. ${ }^{5}$ Igualmente se resaltaba en editoriales la movilización de 1968 como una de las causas de que el régimen del PRI buscara establecer

${ }^{3}$ Horacio Espinosa Altamirano. En estos días la historia se llama Ernesto "Che" Guevara. Por Qué?, 8 de noviembre de 1968, p. 30.

${ }^{4}$ Federico Emery. El Partido Comunista Mexicano: sinónimo de traición. Por Qué?, 7 de marzo de 1969 , p. 30.

${ }^{5}$ Rodolfo Montalvo Reyes. El pPs: Partido de oposición. Por Qué?, 13 de junio de 1969 , p. 17.

\section{(이)(1) $(2$}


reformas impulsadas por Carlos Madrazo luego de $1968 .{ }^{6}$ Sin que estos ejemplos trivializaran la exaltación del movimiento, el evento era más un vehículo para enrostrarse la incapacidad de la acción, la negligencia y la cobardía, a menudo apelando a alegorías donde se presentaba lo femenino como debilidad; en ultimas se trataba de un discurso de pugna con una profunda carga de funcionalidad dentro de las diatribas de la izquierda mexicana.

Con respecto a las mujeres, la celebración del heroísmo del movimiento estudiantil fue exaltado por Carmen de la Guardia, escritora que comparó esa lucha contra "un régimen testarudo y violento" con una gesta de orden sobrenatural, mesiánico, pues aseguraba que "los jóvenes escriben un nuevo evangelio" aun sin el concurso de sus profetas. El carácter ecuménico de la revolución reposaba en esa universalidad de los principios de libertad y la justicia social, y que despertaba la ilusión por ser obra de quienes se esperaban los grandes cambios que la sociedad aguardaba desde hacía décadas. ${ }^{7}$ Unas semanas después, fue Gabriel Paz quien entregó un balance sobre el papel de la mujer en la revolución, donde se asociaba la necesidad de romper las cadenas de un sometimiento a través de la adquisición de "una conciencia de sí misma" y la "ampliación del horizonte profesional femenino". Pese a ese llamado por enaltecer a la mujer asignándole un papel protagónico en el cambio social a través de profesiones que abrieran el ámbito público -como el periodismo-, la revista mantuvo en general un discreto número de contribuciones femeninas.

El problema estaba en que recaía sobre una profesión en la que predominaba el trabajo masculino, o al menos eran quienes recibían el reconocimiento social por su labor, y en la que pese al horizonte moral y ético de equidad, las posibilidades de trascender las restricciones y prejuicios formados en torno a las mujeres impidieron que superaran el umbral de la ilusión. En el periodismo de los años 1960 lo viril se constituyó en un carácter particular de lo masculino, cuya función social está cargada de sentidos, signos e inflexiones del lenguaje culturalmente asignados, y que a nivel ideológico se emparenta con las formas de dominación y subordinación. Jóvenes y mujeres desempeñan así un papel marginado del centro de atención del poder y sus signos que configura la masculinidad como dominante. En el caso de

${ }^{6}$ Editorial. La nueva juventud "revolucionaria”. Por Qué?, 17 de enero de 1969, p. 26.

${ }^{7}$ Carmen de la Guardia. Los jóvenes han escrito el nuevo evangelio. Por Qué?, 20 de diciembre de 1968, p. 11.

${ }^{8}$ Gabriel Paz. La mujer: una revolución a medias. Por Qué?, 17 de enero de 1969, p. 30.

\section{(ㅇ)(1) $\$$}


México, como imposición cultural y profesional el periodismo heroico tenía en la orientación revolucionaria un objetivo, y para su alcance exacerbaba características como el enfrentar el riesgo, la fuerza y actitudes temerarias, por lo que el reconocimiento público se limitaba a los hombres involucrados. Así, la virilidad del periodista heroico resulta de una construcción social de la subordinación de género que somete a las mujeres o jóvenes a articularse en desventaja a procesos políticos y sociales, y donde la valentía viril revolucionaria serviría para validar el proceso una y otra vez de manera cíclica. Aunque este proceso no es único del caso mexicano, sí resulta de interés a la luz de las investigaciones que empiezan a dar cuenta de esa faceta que terminó por afectar la posibilidad de hacer del discurso público de la izquierda una realidad en construcción (Castillo, 2013, p. 173; Cohen y Frazier, 1993, pp. 86-93; 2004, pp. 591-623).

El relato personal entregado por el fotógrafo Armando Salgado nos ofrece pistas sobre la forma como el riesgo en el ejercicio de la profesión, y el flujo constante de adrenalina, eran insumos que ponían a prueba a cada momento el temple de periodistas y reporteros gráficos, por lo que se trataba de un oficio en el que las mujeres habrían tenido que soportar una presión no sólo de parte de los organismos de seguridad y la sociedad, sino además de sus colegas. Allí Salgado hace alusión a la cotidiana faena de inmiscuirse en las actividades de los bajos fondos de la ciudad, donde ocasionalmente se permitía combinar trabajo con el placer de fotografiar "el mundo de corredores y pasillos, de camerinos y tramoyas, de pésimos olores y encueratrices decadentes", donde "da risa loca recordar cómo sufría al tomar esos esperpentos que tan dignamente se prestaban a posar, y todo porque yo ignoraba que las 'buenotas' ya estaban amarchantadas". Luego, Salgado tendría oportunidad de hacer las veces de reportero gráfico con tonos artísticos en los Estudios Churubusco, "donde tuve mejor oportunidad con las rorras" luego de que se percataron de que lo único que le interesaba al fotógrafo eran las fotos (Salgado, 1990, p. 20).

Más allá de estas infidencias que trascienden lo netamente periodístico, pero que arrojan de algún modo luz sobre lo arraigado de las percepciones peyorativas de los hombres con respecto a las mujeres en México, en su relato Armando Salgado evoca los constantes riesgos a los que Mario Menéndez lo expuso cuando le dio una comisión para acompañarlo en 1967 en una ronda de entrevistas que pactó con el grupo armado del Ejército de Liberación Nacional (eLN) en las montañas de Colombia (Arenas, 1971, pp. 34-42; Castillo, 2013, pp. 150-151; Medina 1996, pp. 85-88). Aunque no reconoce esa exposición

\section{(이요 $\circledast$}


que le impuso el director de Por Qué?, el acto temerario en el que Armando Salgado debió enfrentar los riesgos propios de una acción guerrillera y la posibilidad constante de su captura, el fotógrafo asumió esas experiencias como una oportunidad de refrendar sus concepciones políticas a través del despliegue de valor y virilidad. Los hechos ocurridos en la primera mitad de 1967, y que llegarían al público en la tercera semana de julio del mismo año, constituían una sorpresa a cada instante para el fotógrafo, quien tenía poca información sobre toda la operación en la que estaba envuelto -seguramente una medida de seguridad tomada por la insurgencia para evitar delaciones en caso de caer en manos de los organismos de inteligencia colombianos-, cual si se tratase de un guerrillero en misión bajo el peligro de sucumbir en el intento.

En el relato de Armando Salgado aflora la constante del riesgo, con un sabor que mezcla el compromiso y la sangre fría de continuar en un propósito en el que el ofrecimiento de los micrófonos y las páginas de una publicación era una expresión de apoyo para que la insurgencia pudiera emitir el mensaje de sus motivos de lucha, colmar la desinformación internacional de cara a las adversidades soportadas por cada grupo radical, cada foco armado o guerrilla insurreccional. Ese enfrentamiento del temor tiene sin embargo dos facetas que merecen ser mencionadas. De una parte, el liderazgo y comprensión del proceso por parte de Mario Menéndez, y la ignorancia de Armando Salgado. El primero fue quien auspició tan audaces entrevistas, colmando sus bolsillos de dinero para que en el derroche pasara desapercibido viajando por Guatemala, Panamá y finalmente Bogotá. En el primer caso, el del director Mario Menéndez, su versión es más esquiva y se ha rodeado con el paso de los años de enigmas que mitifican la acción. Si al director de Por Qué? se le reconoce por algo, es por los señalamientos de ser parte de la Agencia Central de Inteligencia (CIA por sus siglas en inglés), un ejercicio de sindicación rutinario de los organismos de seguridad que no dudaban en propagar anatemas contra los detractores del régimen. Así, el camino para la formación de un mito hace provecho de la sombra de duda que se cierne sobre el periodista, lo que robustece la historia para la posteridad. A Mario Menéndez se le creó aún más fama en Colombia, lo que le da más trascendencia a su figura (Castillo, 2013, pp. 152-153; Medina, 1996, pp. 120-122; Rodríguez, 2007, pp. 207-219; Salgado, 1990, pp. 45-48).

En el segundo caso, la función del reportero gráfico como partícipe en la acción de complementar esa difusión fue una oportunidad de confrontar la versión oficial, con pruebas para demostrar los alcances de la lucha revolucionaria. El escrito del fotógrafo Armando Salgado ofrece así, de primera mano, la experiencia de confrontar el miedo y el cumplimiento de un deber,

\section{()(1) (}


que aparece como un llamado a cumplir con un destino histórico que poco parece asociarse con la voluntad y/o conciencia de los hechos. Se trata de la parte más básica de la clandestinidad al menos en la forma en que operan las guerrillas. Pese a que el relato está marcado por el trauma de la tortura y tormentos psicológicos posteriores que seguramente hacen del texto un ejercicio de alivio (Ortega, 2011, pp. 17-20), su lectura deja un aura de heroísmo que en el fondo corresponde a los riesgos a los que lo expuso su jefe Mario Menéndez, y que luego fueron asumidos con vehemencia, pues no era clara la alineación político-ideológica del fotógrafo previo a los hechos que relató. Si bien tenía una conciencia social, esta no aparece como un antecedente; pero la afinidad laboral causaba vínculos tan fuertes como en cualquier otro escenario. El problema está en el trauma sufrido, sus secuelas, y la inserción al proceso de forma inesperada.

Estos ejemplos, así como las definiciones aportadas en esta investigación sobre la subjetividad revolucionaria y el periodismo heroico, dan cuenta de los procesos internos del periodismo sólo a través de su detección en evidencia del orden público. De momento, son elementos que esclarecen no sólo la marginación de mujeres y jóvenes, sino las expectativas que condicionaban el accionar masculino, con todo el andamiaje que reforzaba su virilidad, sea en lo exterior, o en la concepción de su papel político y social en la construcción de un ideal de revolución.

\section{HACIA UNA INTERPRETACIÓN DEL FENÓMENO}

Como lo señala María Josefina Portillo-Saldaña, la proliferación de narrativas del cambio social promediando el siglo xx usan como eje nociones como "revolución", "progreso" y "desarrollo", que son más o menos flexibles o susceptibles de interpretaciones de actores -a menudo antagónicos-, lo que da como resultado una constante mutación de la forma como tales visiones del mundo son interiorizadas/trasformadas/expresadas o incluso instrumentalizadas por los individuos (Saldaña, 2003, pp. 11-34). En otras palabras, la simultaneidad de concepciones del ser "revolucionario" y su legitimación en el ámbito político, ha gestado una variedad de manifestaciones de la subjetividad revolucionaria. "Revolución" es una de tantas palabras manoseadas con diversos propósitos. Esa polisemia también se acompaña de narrativas que le dan fuerza y vigencia social. Una de las formas como se abordan esas subjetividades es a partir de la idealización de los procesos de acción y/o

\section{(이요 $(2$}


reflexión, espacio en el que lo heroico resulta ser el cemento que cristaliza los paradigmas que movilizan a los individuos en la política contemporánea (Saldaña, 2003, pp. 201-214). En el contexto mexicano, y específicamente en el mundo de los periodistas políticos e intelectuales, este "ser revolucionario" significó una marca de distinción y aceptación en una comunidad homosocial que privilegiaba ciertos preceptos morales, valores y virtudes, y una audacia expresada en la disipación del temor a los efectos de la represión aun si implicaba llegar a la muerte o a la pérdida de la libertad. En otras palabras, el periodismo heroico de izquierdas comenzaba a definir subjetividades, dóciles en términos políticos, e ideológicamente asimilables con el espíritu de la época.

En una línea de análisis similar, Deborah Cohen y Lessie Jo Frazier, en lugar de interesarse por la proliferación de narrativas sobre "lo revolucionario", prefieren identificar los motivos y funciones de las innumerables versiones de "el 68". En el caso específico del movimiento estudiantil, y como resultado de innumerables presos políticos tras las oleadas de represión, las narrativas del sacrificio son predominantemente ofrecidas desde la perspectiva masculina. Con sus hombres victimizados por el puño de hierro del régimen, las mujeres se mantuvieron en el ámbito del activismo público de forma constante, pero de ello poco se sabe. En su lugar, la historia nos cuenta que los líderes de la movilización fueron hombres, pero no se menciona ni la cotidianidad de esos sitios de reclusión, ni el tráfico de cartas, comidas, abrazos y voces de aliento que ellas llevaron. Tampoco se recuerda que los comités del movimiento estudiantil tuvieron la fuerza y se ganaron el favor popular por las campañas de difusión masiva que orquestaron las mujeres, que incluían un sistema refinado de información, transmisión de comida, propaganda y apoyo social, y que eran potentes por esa raíz social, y por ende difíciles de disipar por las fuerzas represoras del poder aciago.

Aquellos cuyos nombres pasaron a la historia como mártires surgieron en el ámbito privado de la Cárcel Preventiva y Lecumberri, pero esas narrativas no se compadecen con quienes cargaron el peso público del sometimiento brutal impuesto por la represión gubernamental (Cohen y Frazier, 1993, pp. 96-99; 2004, pp. 600-602). Durante y después de 1968 no se construyeron narrativas del fenómeno donde se balanceara el legado de las mujeres como protagonistas esenciales. ${ }^{9}$ En su lugar, abundan las historias

9 El caso del trabajo de Elena Poniatowska (2009), La noche de Tlatelolco, es quiza sui generis, como lo es la forma en que la periodista y escritora se había involucrado para entonces

\section{()(1) $(2$}


que evocan las tribulaciones de la cárcel, dictadas desde los diversos comités de agitación, pero no dan cuenta de la otra gran mitad de lo ocurrido, y se eclipsa la experiencia desde la perspectiva de las mujeres pese a que fueron centrales para eludir la represión y hacer posible el vínculo social comunitario en Ciudad Universitaria y luego en los andenes de espera frente a las cárceles (Bolaño, 1999; González de Alba, 1971). La narrativa predominante hoy en día es la que publicaron los varones, donde el heroísmo estuvo limitado a la reflexión obsesiva y la discusión teórica impuestas por el enclaustramiento. La compulsión de versiones sigue el mismo patrón, casi ineludiblemente tienen a un héroe. Las heroínas sin embargo son las de historias que aún circulan en los recuerdos, y no por carecer de las toneladas de papel de las otras versiones publicadas han dejado de existir y tener vigencia en la forma de memorias colectivas.

Estas narrativas marginalizaron la percepción/contribución femenina durante todo el proceso. Dichas narrativas crean imágenes limitadas que sólo pueden promover una frágil concepción de los procesos de cambio social, así como una miope percepción de "la revolución". Con respecto a los espacios de legitimación, Cohen y Frazier (1993, 2004) realizan un escrutinio de la cárcel como espacio que asignaba la estatua moral para liderar el proceso, y ante la que las mujeres se prosternaban para colaborar, ayudar, pero no para construir el movimiento al menos en el discurso público y las versiones de "el 68 ".

De esta forma, el ideal del Hombre Nuevo y el periodista heroico estaban atravesados por grietas, pues en su construcción se evadió la realidad de una colaboración femenina estrecha, mientras afirma una perspectiva de poder y dominación que subyuga a las mujeres y la realidad de su participación. Algo similar ocurrió con los jóvenes, a quienes se les paternalizaba y adiestraba para la revolución sin permitirles evocar su concepción propia

en los altos círculos intelectuales mexicanos. La autora devino una de las voces más representativas del movimiento estudiantil a través de formas narrativas que apelaban a la versión directa de los involucrados. Esto marcó de forma significativa la apropiación narrativa de los hechos, a la vez que implicó una relacion innovadora de los intelectuales con las capas sociales históricamente silenciadas en las versiones oficiales que circulaban en el periodismo mexicano en los años 1960. Un ejemplo de esto fue la manera como la escritora se involucró directamente en ese rescate de la visión de los marginados que se puede identificar, por ejemplo, en las entrevistas y escritos que publicó en La Cultura en Mexico, en el marco de los escándalos ocurridos entre 1963 y 1965 luego de la publicación de Los hijos de Sánchez y la Antropologia de la pobreza, del investigador estadunidense Oscar Lewis. Allí el régimen respondió con estrategias represivas que sin embargo no son materia de investigación en este artículo.

\section{(이요 $(2$}


del proceso. No en vano las loas al heroísmo de los presos políticos devinieron a lo largo de las décadas de 1960 y 1970 en las voces y el tema más destacados para el periodismo de oposición. Su capacidad de poner a un lado los riesgos es un proceso que en su análisis es necesario confrontarlo con la función del periodismo heroico y la construcción de una subjetividad volcada a atender a los presos políticos como gurúes y líderes morales en un contexto de lucha desigual, por lo cual la prisión era un salto obligado en la sublimación del ser revolucionario. Este artículo de alguna forma trata de acercarse a este fenómeno.

El trabajo de estas investigadoras estadunidenses abrió un sendero importante para comprender la configuración de subjetividades heroicas en el ámbito de disputa por la construcción de la ilusión política del movimiento de 1968. En los trabajos de Cohen y Frazier (1993, 2004), las autoras pasan por alto la relación que la izquierda había establecido con el nuevo humanismo promovida en América Latina por la revolución cubana en la década de 1960, algo que les impidió vislumbrar la manera como las izquierdas asimilaron localmente la retórica socialista del Hombre Nuevo, prototipo encarnado por ejemplo en las figuras de Ernesto "Che" Guevara y Regis Debray. El Hombre Nuevo estaba también alimentado en una influencia ideológica que articulaba versiones similares provenientes de los trabajos más de corte teórico de Frantz Fanon, Jean Paul Sartre y, para el caso de Latinoamérica, el impacto del trabajo y participación política de Régis Debray en Francia, Cuba y Bolivia. Este periodista e intelectual incidió en la percepción de una generación de profesionales políticamente activos que durante la primera mitad de la década de 1960 se inspiraron en sus trabajos sobre teoría política y táctica insurgente. Como periodista se lo admiraba en los corredores de Política y Por Qué? como paradigma de acción y compromiso, pues representaba en la práctica del periodismo el salto del sillón del intelectual reflexionando a los campos de lucha política e insurreccional. Al vencer un miedo y obviar el peligro, Régis Debray dio un salto al enfrentar el peligro que representaba cubrir una guerra insurgente. Lo que hacía Mario Menéndez en Por Qué? no era diferente. Durante la captura de Régis Debray el periodismo mexicano revistió su hazaña de un aura de entrega y compromiso sin límites, al presentarlo como una síntesis de subjetividad heroica, alternativa a la del guerrillero sacrificado con un arma en sus manos, en especial cuando era imposible para escritores, académicos y periodistas seguir los mandatos del compromiso revolucionario como lo hizo Ernesto "Che" Guevara o incluso Camilo Torres en Colombia.

\section{(이)(1) $(2$}


La exaltación de las luchas estudiantiles y campesinas en México estuvo acompañada por celebraciones del legado revolucionario de personajes paradigmáticos, y no sólo aquellos que en Cuba implantaron un ejercicio de rebelión antimperialista que los periodistas admiraban, pues diversificaron ese espectro al incluir homenajes a prohombres como lo fueron Camilo Torres con el elv en Colombia ${ }^{10}$ y Augusto César Sandino en Nicaragua. ${ }^{11}$ Tampoco faltaron exaltaciones de héroes locales, en los que se invitaba a plasmar la toma de conciencia en actos, ${ }^{12}$ se homenajeaba a líderes sociales caídos como en el caso de Rubén Jaramillo cuando se cumplía un aniversario de su asesinato, ${ }^{13}$ o el cubrimiento de actos de rebeldía estudiantil en las provincias del país. ${ }^{14}$ Sin embargo, el heroísmo de la izquierda mexicana tenía para su enaltecimiento a los grupos guerrilleros que florecían, particularmente en el estado de Guerrero, y a los líderes que el régimen acribillaba y con los que sembraba de terror las poblaciones rurales. ${ }^{15} \mathrm{~A}$ estos procesos Por Qué? les dedicó amplios espacios en la sección editorial, ya que como resultado de la represión el anonimato era la mejor manera de mantener la seguridad de los reportajes. ${ }^{16}$ Finalmente, desde la cárcel Fausto Trejo denunció un plan que se urdía para boicotear la huelga de hambre que encabezaba, por lo que recurrió a invocar la acción juvenil para hacer público el riesgo que corría su vida. ${ }^{17}$ En efecto, a los pocos días de su publicación, la huelga de hambre fue boicoteada en las primeras horas de 1970 por presos de las crujías de delitos comunes y uno que otro agente del orden constitucional

10 Carlos Núñez y José Joyero. Diálogo con Isabel Restrepo. Vida, pasión y muerte de Camilo Torres. Por Qué?, 7 de marzo de 1969, p. 46.

${ }_{11}$ Horacio Espinosa Altamirano. Sandino: ciudadano ejemplar de América. Por Qué?, 7 de marzo de 1969, p. 38.

${ }^{12}$ Horacio Espinosa Altamirano. En torno a la lucha heroica. Por Qué?, 14 de febrero de 1969, p. 7; Jorge Correa Bravo. Revolución y anarquía. Por Qué?, 4 de julio de 1969, p. 18; Editorial. El terrorismo no fue revolucionario. Por Qué?, 2 de octubre de 1969, p. 4.

13 Editorial. La matanza de Xochicalco, 7 años después. Por Qué?, 30 de mayo de 1969, p. 4.

14 Abel Medina. El gobierno de Guadalajara y la corrupción en ese estado. Por Qué?, 9 de abril de 1969 , p. 26.

${ }_{15}$ Marco Antonio Vargas. Estado de Guerrero: a dos años de la matanza de copreros. Por Qué?, 11 de mayo de 1969, p. 14; Marco Antonio Vargas. En Guerrero: la muerte de un periodista. Por Qué?, 13 de noviembre de 1969, p. 21.

16 Editorial. Por Qué?, 24 de mayo de 1969, p. 16; Editorial. Habla Genaro Vázquez a la opinión pública. Por Qué?, 6 de junio de 1969, pp. 9-11; Editorial. Las guerrillas de Chihuahua I. Por Qué?, 20 de diciembre de 1968, pp. 9-12; Editorial. Las guerrillas de Chihuahua II. Por Qué?, 27 de diciembre de 1968, pp. 9-14.

17 Fausto Trejo. Los jóvenes de México y nuestra huelga de hambre. Por Qué?, 25 de diciembre de 1969, p. 10.

\section{(ㅇ)(1) $\$$}


y democrático, como un preludio de las pisadas fuertes propias de la transición del cabecilla del régimen.

Estos textos elevaban la moral de la lucha política juvenil en México mientras redimensionaban el discurso periodístico en torno a los nuevos referentes de lucha y veneración que eran característicos de procesos revolucionarios. Sin embargo, fue la pluma de José Revueltas la que suministró aire y energías a los luchadores jóvenes sometidos al encierro. ${ }^{18}$ Para entonces, la izquierda institucional criticada en la revista Por Qué? mantenía al escritor marginado, pese a que este era en buena medida el insumo moral que encendió la rebeldía juvenil durante la década de 1960. Este fue un factor adicional para que la revista rápidamente se ganara el desprecio de sectores de la izquierda que, aunque beneficiados con la reanimación de la protesta juvenil, carecía de líderes que los guiara y espacios de expresión gracias a los ajustes en la censura que implementaba el gobierno de Gustavo Díaz Ordaz y del entrante Luis Echeverría. En otras palabras, la imagen de mártir que se difundió en la prensa de oposición durante la década de 1960 sirvió de paradigma sustituto para intelectuales intensamente involucrados con hacer, hablar de, o describir la revolución de izquierdas, en lugar de ir a pelearla en la guerra de guerrillas. Naturalmente no abundaron ejemplos que siguieran sus pasos.

En resumen, en el periodismo de izquierda de las décadas de 1960 y 1970, "lo revolucionario" no sólo se manifestó como exaltación de la masculinidad de los directores, sino que fue una epifanía de la construcción interna de relaciones de poder y discursos públicos que sirvió para apalancar a los periodistas como héroes, mientras se silenciaba el papel de mujeres y jóvenes que fueron actores centrales del proceso de cambio político y de la demanda por una renovación en el liderazgo generacional existente en México. Para la investigación aquí sustanciada, estos elementos son de interés a la hora de comprender la forma como la lucha revolucionaria se constituyó en un campo homosocial de disputa, en el que las mujeres y los jóvenes tuvieron un papel marginal pese a constituir la fuerza movilizadora de las protestas de 1968 y de los cambios políticos que siguieron tras su nefasto aplastamiento. En seguida veremos algunas de las especificidades de este proceso, reflejadas en Por Qué?, primero al observar la plantilla de colaboradores, y luego en ejemplos específicos del discurso desplegado en sus artículos.

${ }^{18}$ José Revueltas. A los estudiantes presos. Por Qué?, 6 de marzo de 1970, p. 18.

\section{(ㅇ)(1) $\$$}




\section{HÉROES SIN HEROÍNAS: JÓVENES Y MUJERES EN LOS DEBATES Y DESAVENENCIAS DE POR QUÉ?}

La temprana reclusión de Por Qué? en los fríos sótanos de la subsistencia periodística marcó su carácter editorial y la percepción pública que de su contenido tenía la sociedad mexicana. Este fue entonces un factor que serviría de contrapeso a su debilidad en el tratamiento analítico de temas políticos, y un impulso para la radicalización en el abordaje de temas comúnmente monopolizados por la prensa de los partidos de izquierda, en particular en aquellos delicados como la lucha armada, la participación femenina en la lucha revolucionaria, y el papel de la juventud en la revitalización de la oposición. Sus páginas eran débiles réplicas de temas periodísticos candentes en otros escenarios internacionales, tales como la importancia de la mujer y los jóvenes en la vida nacional, miradas teóricas alternativas al marxismo, y el debate sobre la legalidad de la marihuana. El tratamiento de controversias como la del hipismo y la vida de comunidades contraculturales en California, el uso de drogas, y el apoyo a sectores de artistas que no estaban relacionados con compromisos políticos definidos, fueron factores que pusieron a prueba el valor de sus páginas, sobre todo a los ojos de una izquierda mexicana urgida por aprovechar vasos comunicantes con la población.

Temprano, Por Qué? fue sindicada -por el régimen y por los sectores de la izquierda que no resultaban bien retratados en sus páginas- de ser espejo de la cultura decadente del imperialismo, además de recibir apelativos desdeñosos que insinuaban que su formato -inicialmente tuvo un tamaño grande- se asemejaba más a las revistas de variedades apropiadas para un salón de belleza antes que para la maleta del estudiante activista. La quimera de su tamaño inicial $(25 \times 35 \mathrm{~cm})$ sólo duró lo que los primeros números dedicados a reportajes gráficos sobre las artes, el cine y la crónica urbana, para luego optar por el formato definitivo de $1 / 8$. A las controversias en las que intentaba mediar, se le suma la parcial ausencia de una línea editorial, una sección discontinua y a menudo espontánea en el tratamiento de la actualidad semanal que careció de uniformidad en el tono usado por sus columnistas así como en las posiciones que buscaba afirmar. Los colaboradores de Por Qué? representaban una muestra de las divisiones de la izquierda, y esto se manifestó en el carácter de las discusiones registradas en sus páginas; aquí privilegiaremos la presentación de aquellos tópicos relacionados con la participación juvenil en política.

\section{(이요 $(3$}


Mario Menéndez se sirvió a menudo de sus familiares para colmar sus páginas, pero pronto se fueron acercando a su círculo reconocidos contribuidores que más parecían escenificar un desfile de fugitivos de los múltiples rituales de escisión partidistas de la izquierda tradicional mexicana. Entre otros, contó con aportes de Ramón Costa Ayube, Armando Gutiérrez Pasos, Miguel Ángel Menéndez, Jorge Larrea Bravo, Carmen de la Guardia, Carlos Altamirano, Rodolfo Montalvo Reyes y Horacio Espinosa Altamirano. Como presos políticos desfilaron por su parrilla de colaboradores Fausto Trejo, Demetrio Vallejo, Federico Emery y José Revueltas. Textos de René Alis y Leopoldo Ayala sobresalían en el abordaje a las artes y la cultura; así como eran notables los artículos tomados de Prensa Latina -en particular reportajes por entregas de Francisco Portela y Héctor Zumbado- que iluminaron el sendero juvenil con la luz que irradiaba desde la Cuba revolucionaria, en especial desde que allí llegó por un exilio forzado el director Mario Menéndez, quien primero fue hecho prisionero con acusaciones poco claras del gobierno respecto a su participación en una serie de atentados explosivos que sacudieron el periodismo mexicano en la transición de gobiernos entre Gustavo Díaz Ordaz y Luis Echeverría.

Los periodistas Marco Antonio Vargas, Baloy Mayo Ventura, Augusto Bejarano y Julián Gallardo aportaron escritos centrales en la época de la radicalización de la línea editorial en el cambio de década; temas como el inquietante desorden social en el estado de Guerrero fueron acompañados de comunicados y fotos que hacían retorcerse de ira al personal de la Secretaría de Gobierno y a los organismos de defensa. En efecto, los verdugos de los opositores habrían preferido tener en sus manos los cuellos de líderes insurgentes de México, Colombia y Venezuela, para también retorcerlos en métodos de tortura en los que ya eran diestros practicantes; esto marcó la relación de los editores con los rectores políticos del país.

La rápida asimilación que hizo Por Qué? de algunos de los reclamos de la juventud irritada con el presidente de turno fueron fundamentales para posicionarla como una de las principales publicaciones que acompañó al movimiento estudiantil de ese año (Castillo, 2013, pp. 149-153; Rodríguez, 2007, pp. 207-220). A pesar de querer vincularse desde temprano con los sectores marginados de la revista Política y los partidos tradicionales de la izquierda, y pese a que intentaba exaltar el papel revolucionario de las mujeres y los jóvenes, este discurso no pasó de la retórica. Durante su existencia, Por Qué? apenas incluyó unas cuantas mujeres en su plantilla de escritores, de las cuales vale la pena mencionar a la brasileña Vânia Bambirra, que por entonces tenía

\section{(1)(1)}


una agenda activa junto a los promotores de la teología de la liberación en Chile, México y su país natal. En cuanto a los jóvenes, de la mano de Heberto Castillo y el movimiento de 1968 se alinearon numerosos colaboradores, y el cuerpo editorial puede considerarse de espíritu juvenil por la vitalidad de sus escritos que animaron a la juventud del país.

Aun así, en Por Qué? y en las fuerzas de oposición mexicana las jerarquías, ideologías y distinciones generacionales y socioeconómicas marcaban la influencia y participación de cada joven lector o colaborador. Vale anotar que el espíritu ambicioso e informal de la revista era asociado por la vieja guardia de la izquierda mexicana como un innegable indicio de su condición ecléctica, revisionista en términos teóricos, e irrespetuoso de las tradiciones de lucha de los adultos que marcaban el paso de la oposición de izquierdas en el país. ${ }^{19}$ Esta pléyade del periodismo de la izquierda no era un grupo compacto, y con el pasar de los meses, tras la masacre de Tlatelolco, algunos se apartaron de la publicación para evitar que las tensiones con aquellos afines a la causa revolucionaria superaran los odios contra el régimen oficial. ${ }^{20} \mathrm{En}$ el caso de Por Qué?, el retiro más sensible fue el de Heberto Castillo a raíz de un artículo de Rafael Tinoco en el que lanzó críticas que mancillaron la imagen del "tata" de la revolución Lázaro Cárdenas en el momento en que estaban aún frescas las flores y las lágrimas derramadas sobre su tumba. ${ }^{21}$ Previo a este artículo, donde en tono sarcástico consideró que "toca decir la verdad sobre Cárdenas. Explicar su mito y sus hechos [...] la forma como se lo erige como un creador, el paladín, dador de tierra, sagrado tata, dispensador de vida, liberador. [Pero] el mito mantiene líderes represores, que controla la dignidad de los mexicanos", 22 el periodista había lanzado dardos incómodos contra la izquierda mexicana ${ }^{23}$ que terminaron por exasperar a Heberto Castillo, quien se retiró de la publicación.

${ }^{19}$ Horacio Espinosa Altamirano. La revolución mexicana: ahí está el detalle. Por Qué?, 27 de noviembre de 1969, p. 13; Demetrio Vallejo. Izquierda, derecha, centro, o el culto a la personalidad. Por Qué?, 20 de noviembre de 1969, p. 14.

${ }^{20}$ Federico Emery. El Partido Comunista Mexicano: sinónimo de traición. Por Qué?, 7 de marzo de 1969, p. 30; Rodolfo Montalvo Reyes. El pps: Partido de oposición. Por Qué?, 13 de junio de 1969, p. 17.

${ }^{21}$ Rafael Tinoco. El verdadero Cárdenas. Por Qué?, 5 de noviembre de 1970, p. 23.

${ }^{22}$ Rafael Tinoco. El verdadero Cárdenas. Por Qué?, 5 de noviembre de 1970, p. 23.

${ }^{23}$ Rafael Tinoco. La izquierda oficial, los amos de la confusión en México. Por Qué?, 8 de octubre 1970, pp. 3-5; Rafael Tinoco. Miedo a la revolución, enfermedad de los partidos comunistas. Por Qué?, 22 de octubre de 1970, pp. 11-12.

\section{(ㅇ)(1) $\$$}


El director Mario Menéndez reparó en una respuesta editorial, en la que señaló a Heberto de haber criticado a Lázaro Cárdenas en su momento, por lo que había "movido el lodo de la desvergüenza", de allí que era necesario "ser implacable en los juicios para así hacer la purificación de nuestra historia”. ${ }^{24}$ Esta separación significó un giro drástico en el tono editorial de Por Qué?, pues se afilaron sus dardos contra la izquierda tradicional, y particularmente contra el PPS, el PCM, el Centro de Estudios Mexicanos, los remanentes del MLN y sus voceros luego de la desaparición de Política en 1967. Esto significó una escisión que agudizaba la crisis de la izquierda por efectos de contradicciones internas. La nueva línea editorial la orientó la pluma temeraria de Rafael Tinoco, apoyado por textos también polémicos de Horacio Espinosa Altamirano, Juan Navarro Altamirano, León Guzmán e Ysaías Rojas Delgado, que de forma regular lanzaban fuertes críticas a los fragmentos de una izquierda ya de por sí diezmada por la represión, la cooptación, el exilio o el encierro.

Este posicionamiento le significaría a Por Qué? un futuro espinoso ante las dudas que la izquierda mexicana cerniría sobre sus colaboradores y valor informativo, en particular por parte de aquellos afiliado a círculos intelectuales destacados ${ }^{25}$ y por un tono periodístico radical en el que se pasó a un dogmatismo cebado contra el trotskismo, y que hizo pasar a autores teóricos como Herbert Marcuse del cielo de la exaltación al infierno de la condena como un agente de la CIA poco ortodoxo dentro del marxismo. ${ }^{26}$ Esto ocurrió luego de que en una entrevista que el intelectual dio a Excélsior, sus apreciaciones no se adecuaran a la línea dura asumida por la publicación, por lo que desdeñaron sus comentarios. ${ }^{27}$

El eclecticismo que antes ponía a Por Qué? al garete entre la teología de la liberación, la exaltación de la insurgencia latinoamericana, la crítica sistemática de los partidos comunistas de la región en todas sus variantes y estirpes, y la animadversión frente a los partidos políticos tradicionales mexicanos alineados en un amplia definición de "la izquierda", representa-

${ }^{24}$ Mario Menéndez. Respuesta a un oportunista. Por Qué?, 25 de noviembre de 1970, pp. 4-5.

${ }^{25}$ Editorial. Heberto Castillo, de oportunista a delator. Por Qué?, 23 de marzo de 1972, p. 12 .

${ }^{26}$ Ysaías Rojas. Marcuse y la revolución socialista mexicana. Por Qué?, 13 de abril de 1972, p. 12.

${ }^{27}$ Editorial. Entrevista a H. Marcuse. Intelectuales, obreros y campesinos. Por Qué?, 13 de abril de 1972, p. 24.

\section{(ㅇ)(1) $\$$}


ba un balance del estado de las fuerzas de oposición progresistas luego de 1968, año de su fundación. También resultaba un indicio de la condición de aislamiento que luego se le impuso desde la izquierda, sumado a la persecución gubernamental. Luego de la radicalización del corte ideológico de la publicación, el aislamiento se agudizó mientras se clamaba a los jóvenes por defender unos ideales desdibujados en el ardor radical que por entonces empezaría a forjar guerrillas urbanas "enfermas" con el entorno social de México.

Las transiciones que tuvo el discurso moral de Por Qué? permiten evidenciar la forma como la interacción editorial con la juventud estuvo ligada tanto a la formación de un marco de subjetividad revolucionario, donde la figura depositaria del heroísmo era el aguerrido periodista de oposición, como al ensalzamiento ulterior de esa idealización de la rebeldía como necesariamente engastada en un molde masculino al que acompañaban valores que oficiaban como atributos que definían la pureza de su compromiso político. A su vez, permite reconocer cómo lo ideológico sirvió como un factor de división entre los colaboradores de la revista.

En los primeros meses de su publicación, las páginas de Por Qué? estuvieron salpicadas de temas controversiales en los que resaltaba una apertura al debate -sin que necesariamente prevaleciera una posición editorial-sobre la importancia de la contracultura y el papel que la juventud podía tener desde propuestas alternativas y críticas de cara a los retos políticos y sociales que ocurrían en México. ${ }^{28}$ Las tendencias del hipismo proponían la contracultura como una necesidad, un alimento espiritual y una forma de expresión de la vida juvenil que legaba en el individuo la capacidad de reflexión filosófica. Tal aproximación filosófica no estaba afiliada al marxismo o a las teorías socialistas, sino a "las filosofías orientales", que eran el mecanismo real por el cual "los hippies logran la paz y la felicidad, en lugar de las drogas", como era generalmente atribuido. ${ }^{29}$ También se buscaba dar al traste con el estereotipo del pelo largo y el vestir desaliñado, pues el hippismo era "más que un membrete dado por la sociedad".

En una línea similar, y sin tomar una posición editorial, en Por Qué? se publicó una nota sobre la demanda juvenil por la legalización de la mari-

${ }^{28}$ Jordi Levi. Por qué soy hippie. Por Qué?, 10 de abril de 1968, pp. 17-19.

${ }^{29}$ Editorial. Motivaciones de la rebeldía estudiantil. Por Qué?, 30 de octubre de 1968, p. 31.

\section{(ㅇ)(1) $\$$}


huana en Londres. ${ }^{30}$ Más adelante en un primer y único episodio de toma de decisiones frente al tema, Jorge Larrea Bravo afirmaba que la manipulación de ese mismo estereotipo era una excusa para reprimir y castigar a la juventud políticamente activa en la UNAM, el IPN y Chapingo, pues según el autor, el tema de las drogas y las cabelleras largas expresaba no un problema juvenil, sino la patológica persecución del régimen contra los jóvenes. ${ }^{31}$ Además de la evidente paranoia que marihuaneros e incriminadores padecían por virtud de la sagrada verdolaga, lo interesante de esta discusión abierta por el columnista de Por Qué? era la inclusión de algunos elementos esgrimidos en trabajos teóricos de Herbert Marcuse que buscaban actualizar el marxismo a la época contemporánea, y simultáneamente ofrecer una crítica a los fundamentos del psicoanálisis freudiano que ofrecía desde décadas atrás un panorama sombrío de la humanidad frente a sus deseos y la represión inherente a las sociedades. El texto de Jorge Larrea Bravo estaba acompañado por un artículo de divulgación sobre la obra de Marcuse..$^{32}$ La lectura de Marcuse no era bien vista por sectores tradicionales de la izquierda, quienes desde publicaciones como Política habían rechazado esa tendencia, mientras los círculos intelectuales que publicaban en La Cultura en México y en Revista de la Universidad tenían posiciones más abiertas frente a propuestas de reformulación ideológica (Sánchez, 2013). Como se señaló previamente, Por Qué? juzgaría la obra del teórico alemán unos años después como un insumo indeseable para los jóvenes en la formación de una conciencia respecto a la lucha política.

Unos meses después, el debate se enriqueció con la contribución de Demetrio Vallejo, que desde una plataforma moral manifestó que "la educación juvenil no es algo subjetivo, sino económico, político y moral". El sindicalista argumentaba desde la cárcel que desde 1968 es claro que "los jóvenes saben lo que quieren", y eso no es otra cosa que un lugar en las decisiones políticas, a lo que el sufragio servirá como una solución. Claro está, tanta libertad no era ofrecida sin efectos colaterales, pues trascendía las decisiones personales, por lo que una estrecha supervisión de los padres de familia y una bien elaborada educación cívica deberían responder a las necesidades e

${ }^{30}$ Editorial. Cinco mil hippies piden marihuana para todos en Londres. Por Qué?, 25 de septiembre de 1968 , p. 11.

${ }^{31}$ Jorge Larrea Bravo. Todos somos hippies drogadictos. Por Qué?, 21 de febrero de 1969, p. 18.

${ }_{32}$ Editorial. Marcuse: sensibilidad y nueva visión del mundo. Por Qué?, 21 de febrero de 1969, p. 40.

\section{()(1) $\$$}


inconformidades sociales. Esta perspectiva resultó una sentencia lapidaria sobre el tema, pues en adelante el problema de las drogas en las páginas de la revista no se volvió a tocar. En la perspectiva de Demetrio Vallejo, las drogas eran una desviación antes que un mecanismo de escape, que ocasionaba en los jóvenes la pérdida de su horizonte político, algo que calificaba el autor como un asunto que no nutría el debate político de fondo porque erosionaba la capacidad de crítica y rebeldía propia de la juventud..$^{33}$

Esto evidencia por lo menos dos fenómenos previamente enunciados en este artículo. De una parte, la influencia que tenían por su estatura moral y sacrificios durante episodios de la lucha social mexicana las columnas de los presos políticos. Esto hacía de los comentarios de Demetrio Vallejo una voz pontifical que prácticamente dio por concluido un tema que nacía y despertaba interés en el público habitual de la revista. En el artículo de Vallejo se nota la contundencia de su opinión de cara a un tema en el cual la juventud, que aparece en el centro del debate, no tiene voz para autodefinirse y mucho menos para adoptar posiciones de debate más allá de la línea dictada por los líderes históricos y/o tradicionales de los movimientos sociales. De otra parte, la forma como Vallejo abordó el papel juvenil en política está subordinado a esquemas de autoridad que precisamente habían sido señalados como nocivos para la izquierda como alternativa durante el movimiento juvenil. En ambos casos la juventud aparecía subordinada y determinada por las fuentes de las que irradiaba la tan deseada autoridad moral como directriz de acción, y sobre todo si ese discurso canónico provenía desde la cárcel

Otra de las figuras políticas que editorializaron desde Por Qué? respecto al lugar de la juventud en la sociedad fue Heberto Castillo. En los meses en los que la agitación estudiantil despertaba en 1968, elaboró un sintético balance de las fuerzas sociales que dentro de la UNAM clamaban por un esfuerzo gubernamental para ampliar y profundizar el papel de la educación superior. En su contribución aseguraba que los jóvenes eran "la materia prima para el desarrollo nacional", y la universidad funcionaba como "fábrica de esa materia prima". En torno al cuestionable manejo administrativo de la UNAM, y la insuficiencia de la reforma universitaria, Heberto Castillo sindicó a los funcionarios como serviles agentes de los intereses estadunidenses en el país, que ignoraban los reclamos de los profesores pese a su experiencia

${ }_{33}$ Demetrio Vallejo. El 'pot' y la rebeldía de la juventud. Por Qué?, 4 de diciembre de 1969, p. 11.

\section{(ㅇ)(1) $\$$}


y conocimiento sobre el rumbo más favorable para la universidad. ${ }^{34} \mathrm{La}$ explosión juvenil avanzaría otros seis meses, para salirse del cauce signado por los partidos políticos tradicionales de la oposición. A pesar de los dictados de Heberto Castillo, que contienen la simiente de una mirada funcional e instrumental de la juventud en el ajedrez de la pugna por el poder en el país, su liderazgo se desplegó durante el acompañamiento que los adultos hicieron del movimiento estudiantil. Merced a su profundo conocimiento de las fuerzas ideológicas desatadas en torno al movimiento de 1968, Heberto Castillo veía con particular temor las disputas que tendían a fraccionar el difícil equilibrio logrado por el movimiento, y el impacto marginal que despertaba entre los adultos, quienes recibían un constante bombardeo de información que demonizaba a la juventud..$^{35}$

Luego de su aprehensión y como preso político, Heberto Castillo mantuvo la fuerza y firmeza de su pluma, sólo que ya no contribuiría para Por Qué? motivado en parte por diferencias con Mario Menéndez respecto a los criterios del camino a seguir luego de la represión de octubre, y por la forma como la radicalización del discurso de la revista no se compadecía con figuras históricas del espectro revolucionario de México. Aquí se nota la divergencia entre dos postulados periodísticos que empuñaban el heraldo de "lo revolucionario" pero con percepciones distintas reflejadas en una misma revista por lo menos hasta 1970. Las desavenencias de estos dos periodistas no se aligeraron a pesar de compartir la condena en la prisión política, algo que reflejaba las profundas diferencias en la concepción del ejercicio de promover una opinión pública y asignarles un papel a los jóvenes en el ámbito político. Mientras Heberto Castillo buscaba un estricto mantenimiento de la agenda esgrimida durante 1968, Mario Menéndez prefería radicalizar sus propuestas de acción. Primero, denunciando al régimen político y los acercamientos que los líderes históricos de la izquierda empezaban a concretar con el gobierno, y luego dándole en sus páginas plena vocería a los grupos insurgentes de Latinoamérica y México. En ambos casos, sin embargo, el ejercicio del periodismo era un refugio seguro para desde allí motivar a las masas -en especial a los jóvenes- a movilizarse desde la distancia inspiradora que proporciona toda plataforma política con ribetes de discurso moral.

${ }^{34}$ Heberto Castillo. ¿Qué pasa en la UnAm? Por Qué?, 10 de abril de 1968, p. 38.

${ }^{35}$ Heberto Castillo. Las tendencias políticas dentro del conflicto estudiantil. Por Qué?, 11 de septiembre de 1968, p. 6.

\section{()(1) $(9$}




\section{CONCLUSIÓN}

Esta investigación ha abordado algunas viñetas de la revista de izquierda Por Qué? (1968-1974) dentro de los procesos de formación de la subjetividad revolucionaria, que llevó en las décadas de 1960 y 1970 a exaltar el periodismo de oposición como una plataforma que validaba la estatura moral de esos líderes de la opinión pública. Este problema se ha abordado desde la particular perspectiva de la subordinación que jóvenes y mujeres padecían en el ámbito político, en especial porque se los consideraba carentes de madurez política, valentía y experiencia, fuentes consideradas como necesarias para desempeñarse con idoneidad dentro del accionar revolucionario de la época. El ideal de madurez política no sólo estaba circunscrito a la predominancia de los liderazgos encabezados por hombres en edad adulta, sino que estaba en parte determinado por una concepción que se empezó a consolidar durante el periodo 1960-1967, cuando en la revista Política se fueron configurando los valores de compromiso y sacrificio que serían exaltados en el periodismo de izquierda.

Entre los elementos de análisis, se propuso el estudio del discurso moral del periodismo de izquierda, el cual estuvo marcado por la necesidad de configurar una mística alternativa que sirviera de sustituto a las doctrinas usadas por el régimen, y que servía de parámetro moral fundamental en México en los años estudiados. El problema central estuvo en que el diálogo que pretendía establecer el periodismo con sus lectores era más bien un monólogo, y estaba atravesado por las percepciones que ponían a mujeres y jóvenes en desventaja para ejercer plenos derechos políticos y ciudadanos, incluso a la hora de hacer oposición al lado de una izquierda profundamente fragmentada. Todo el discurso que se elaboraba como un puente hacia la juventud, estaba marcado por el tono moralista, la condescendencia y el paternalismo, a pesar de que en las revistas consultadas se hacía manifiesta una posición liberal, respetuosa de la mujer y admiradora de la juventud.

El mismo discurso editorial del periodismo heroico opositor exaltaba los rasgos morales del liderazgo como un lugar que se podía vivir sobre todo en la prisión política de Lecumberri, la palestra final en la lucha revolucionaria, el panteón en vida de los moralistas de la revolución. Desde Lecumberri, las salas de prensa en México y las redacciones cubanas que aportaban textos para su publicación en la revista, se talló con sutileza el perfil del periodismo heroico, al punto de que el director de Por Qué?, Mario Menéndez, terminó por repetir el peregrinaje de Regis Debray, David Alfaro Siqueiros, Manuel

\section{(이요 $(3$}


Marcué Pardiñas, Filomeno Mata, Heberto Castillo y Fausto Trejo. ${ }^{36}$ El perfil de heroísmo además circunscribía ese esfuerzo a un papel público masculino consignado en un lugar que no era un hogar sino una escuela, por lo que no se cultivaban los valores del hogar sino los públicos del activismo masculino. Finalmente, las exaltaciones de la masculinidad juvenil en el movimiento volcaban su molde en las figuras gallardas del bronco campesinado de Guerrero y los martirizados presos políticos en Lecumberri, pero no en la calle ni en los pasillos de visitas de las cárceles, pues a las mujeres les faltaba aún lograr la madurez política que era la marca viril de lo revolucionario.

La izquierda mexicana merece observaciones críticas en las que el señalamiento de sus defectos del pasado sirva para corregir el rumbo en el futuro. En estas páginas se ha arrojado luz sobre la ambigüedad de su discurso y prácticas en lo referido a las visiones que mujeres y jóvenes le han merecido en una de las épocas decisivas para su transformación. Si bien la formación de ideales de lucha resulta un proceso natural, es importante identificar la forma como el perfil del periodismo heroico sirvió para asignarles a los jóvenes un papel de vanguardia en la lucha política -incluso aquella que justificaba la insurgencia como la mejor alternativa-, mientras los líderes adultos se enfrascaban en debates teóricos, reflexiones personales y exaltaciones moralizantes que posponían su inserción en la lucha concreta en la arena política, no sólo por la imposibilidad física que implicaba en ocasiones la represión y el encarcelamiento, sino por los obstáculos que implicaba una mentalidad endémica en la izquierda internacional que delegaba la acción a las masas y la reflexión a los intelectuales.

\section{LISTA DE REFERENCIAS}

Agustín, J. (1991). Tragicomedia mexicana I. México: Planeta.

Alba, V. (1967). The mexican revolution and the cartoon. Comparative studies in Society and History, 9(2), 121-136.

Arenas, J. (1971). La guerrilla por dentro. Bogotá: Tercer Mundo.

Bolaño, R. (2004). 2666. Barcelona: Anagrama.

Bolaño, R. (1999). Amuleto. Barcelona: Anagrama.

${ }^{36}$ También se puede incluir a Valentín Campa, Encarnación Pérez, Alberto Lumbreras, entre otros tantos que se iniciaron en el periodismo mientras estuvieron prisioneros.

\section{(ㅇ)(1) $\$$}


Cabrera, P. (2006). Una inquietud de amanecer: literatura y política en México, 1962-1987. México: unam/Plaza y Valdés.

Cano, A. (ed.) (1995). Las publicaciones periódicas y la historia de México. México: UNAM-Hemeroteca Nacional-IIB.

Castillo, A. del (2011). Rodrigo Moya: una mirada documental. México: UnAM-IIE/La Jornada.

Castillo, A. del (2012). Ensayo sobre el movimiento estudiantil de 1968. La fotografía y la construcción de un imaginario. México: Instituto Mora/UnAM-ISSUE.

Castillo A. del (2013). La visión de los vencidos. El movimiento estudiantil de 1968 visto desde la izquierda, el caso de la revista Por qué? En R. Monroy Nasr y A. del Castillo (coords.), Caminar entre fotones. Formas y estilos de la mirada documental (pp. 149-178). México: INAH.

Cohen, D. y Frazier, L. J. (1993). "No sólo cocinábamos...": Historia inédita de la otra mitad del 68. En I. Semo, La transicion interrumpida: México 1968-1988 (pp. 75-105). México: Universidad Iberoamericana/Nueva Imagen.

Cohen, D. y Frazier, L. J. (2004). México 68: Hacia una definición del espacio del movimiento. La masculinidad heroica en la cárcel y las "mujeres" en las calles. Estudios Sociológicos, 22(3), 591-623.

Dahlgren, P. y Sparks, C. (1991). Communication and citizenship: journalism and the public sphere in the New Media age. Nueva York: Routledge.

Díaz, M. (1990). The satiric penny press for workers in Mexico, 1900-1910: A case study in the politicization of popular culture. Journal of Latin American Studies, 22(3), $497-526$.

Fromm, E. (1998). El humanismo como utopía real. Barcelona: Paidós.

González de Alba, L. (1971). Los días y los años. México: Era.

Gutiérrez Fuentes, D. y Borrás Pineda, D. (2001). ¿Por qué voló El Búho? México: UAM-Xochimilco.

Hiriart, H. y Bellinghausen, H. (eds.) (1988). Pensar el 68. México: Cal y Arena.

Jaimes, P. (2012). Los usos de la sátira en la prensa anarquista mexicana del periodo revolucionario: Regeneración, 1910-1918. Pacarina del Sur, 11(3). Recuperado de www. pacarinadelsur.com/home/alma-matinal/425-los-usos-de-la-satira-en-la-prensa-anarquista-mexicana-del-periodo-revolucionario-regeneracion-1910-1918

Kosik, K. (2012). Reflexiones ante diluvianas. México: Itaca.

Leñero, V. (1978). Los periodistas. México: Editorial Joaquín Mortiz.

Medina, C. (1996). ELN una historia contada a dos voces. Bogotá: Quito Editores.

Mraz, J. (1997). Fotografiar el 68. Política y Cultura, 9, 105-128.

Negt, O. y Kluge, A. (1993). Public sphere and experience: toward an analysis of the bourgeois and proletarian public sphere. Minneapolis: University of Minnesota Press.

\section{(ㅇ)(1) $(3$}


Orme, W. (1997). A culture of collusion: An inside look at the Mexican press. Coral Gables/ Boulder: North-South Center Press/Lynne Rienner.

Ortega, F. (2011). Trauma, cultura e historia: Reflexiones interdisciplinarias para el nuevo milenio. Bogotá: CEs-Universidad Nacional de Colombia.

Pérez Montfort, R., Picatto, P. y Castillo, A. del (1997). Hábitos, normas y escándalo: prensa, criminalidad y drogas durante el porfiriato tardío. México: Plaza y Valdés.

Perzabal, C. (1997). De las memorias de Manuel Marcué Pardiñas. México: Editorial Rino.

Poniatowska, E. (2009). La noche de Tlatelolco [1971]. México: Era.

Reynaga, J. (2007). La revolución cubana en México a través de la revista Política: construcción imaginaria de un discurso para América Latina. (Tesis de maestría). Universidad Autónoma del Estado de México.

Rodríguez. R. (1993). Prensa vendida. Los presidentes y los periodistas, 40 años de relaciones. México: Grijalbo.

Rodríguez, J. (2007). La otra guerra secreta: los archivos prohibidos de la prensa y el poder. México: Random House Mondadori.

Rivera Castro, J. (2004). Balance histórico de la revista Problemas Agrícolas e Industriales de México. Tiempo y Escritura. Recuperado de http://www.azc.uam.mx/publica ciones/tye/tye16/art_hist_01.html

Saldaña, M. J. (2003). The revolutionary imagination in the Americas and the age of development. Durham: Duke University Press.

Salgado, A. (1990). Una vida de guerra. México: Editorial Planeta.

Sánchez, J. (enero-julio, 2013). Crisis mística, educación y juventud. La formación del perfil moral del periodismo en la revista Política, 1960-1967. Estudios de Historia Moderna y Contemporánea de México, 45, 97-144.

Trejo, R. (1975). La prensa marginal. México: Ediciones El Caballito.

\section{OTRAS FUENTES}

\section{Bibliografía}

Castillo, A. del (2008). El movimiento estudiantil de 1968 narrado en imágenes. Sociológica, 23(68), 63-114.

Cranston, M. (1972). La nueva izquierda: seis ensayos críticos. México: Diana.

Piccato, P. (2009). The tyranny of opinion: honor in the construction of the Mexican public sphere. Durham: Duke University Press.

Revueltas, J. (1969). El apando. México: Era.

\section{(ㅇ)(1) $\$$}


Schaff, A. (1963). La filosofía del hombre: ¿Marx o Sartre?. México: Grijalbo.

Scherer, J. (1986). Los presidentes. México: Grijalbo.

\section{Hemerografía}

Ramón Costa Ayube. La juventud y la vida, la gran responsabilidad de México. Por Qué?, 10 de abril de 1968, p. 40.

Editorial. Un Estado fascista. Por Qué?, 13 de diciembre de 1968, p. 6.

Horacio Espinosa Altamirano. La revolución mexicana, ahí está el detalle. Por Qué?, 27 de noviembre de 1969, p. 24.

Guerrero. Caciques Asesinos. Por Qué?, 3 de enero de 1969, p. 16.

León Guzmán. Cincuenta y nueve años después todavía sigue insoluta la deuda de la revolución. Por Qué?, 20 de noviembre 1969, p. 10.

Herbert Marcuse. El profeta de la rebeldía juvenil. Por Qué?, 21 de febrero de 1969, p. 40.

Miguel Ángel Menéndez. La patria. Por Qué?, 30 de octubre 1968, p. 6.

Fausto Trejo. El joven y sus sueños. Por Qué?, 24 de enero de 1969, p. 24.

Fausto Trejo. El joven y su despertar II. Por Qué?, 14 de febrero de 1969, p. 7. 